\title{
Memória do desaparecimento: a ditadura no romance K. Relato de uma busca, de Bernardo Kucinski
}

\author{
Joachim Michael
}

\begin{abstract}
RESUMO: O presente estudo mostra que o desaparecimento forçado se encontra no centro do debate literário contemporâneo da ditadura militar (1964-1985) no Brasil. K. Relato de uma busca de (2011) Bernardo Kucinski evidencia que o desaparecimento forçado não é um crime de Estado cuja gravidade possa ser descrita em termos quantitativos. Ao contrário, o livro demonstra que se trata de uma estratégia de extermínio que destrói não só a vítima mas também as pessoas a seu redor e que não se detém no tempo (passado). O romance expõe a destruição humana sem superá-la com a reconstrução daquilo que aconteceu. A memória aqui é a consciência da perda e da incerteza. Nesse sentido, o desaparecimento continua e a destruição também.
\end{abstract}

PALAVRAS-CHAVE: Ditadura militar; Bernardo Kucinski; narrativa

\begin{abstract}
As the present study points out, the contemporary literary debate about the military dictatorship (1964-1985) in Brazil focuses on the phenomenon of forced disappearances. The novel K. Relato de uma busca (2011) by Bernardo Kucinski makes it clear that forced disappearances represent a crime committed by the state that cannot be measured in quantitative terms. Quite on the contrary, the book shows that they are a strategy of extermination that destroys not only the victims but also the persons related to them and that extends from the past up to the present. The novel stages human destruction without overcoming it by reconstructing what happened. Memory here is just the conscience of loss and of uncertainty. In this sense, disappearance goes on - as does destruction.
\end{abstract}




\section{DESAPARECIMENTO E LITERATURA BRASILEIRA}

Há meio século do golpe militar, a literatura brasileira contemporânea rememora de diversas maneiras o período da ditadura entre 1964 e 1985 no país. Quanto ao desaparecimento forçado, destacam-se dois romances que refletem esse instrumento de repressão. Em 2011, Bernardo Kucinksi publica K. Relato de uma busca, ${ }^{1}$ e em 2015 segue Palavras cruzadas, de Guiomar de Grammont. ${ }^{2}$ As duas obras unem algumas semelhanças significativas: ambas têm como tema a busca de um familiar por seu parente desaparecido durante a ditadura militar brasileira nos anos 70 . E os dois romances não enfocam a detenção clandestina de opositores do regime, seguida pela tortura e pela morte das vítimas, mas a perturbação de familiares próximos com a desaparição e a falta de notícias do irmão ou da filha. Ao conferir o protagonismo aos familiares, os textos demonstram que esse crime de Estado estende a vulnerabilidade de seus inimigos a todos aqueles que lhes são próximos. Dito com outras palavras, o aniquilamento vai muito além dos alvos individuais e imediatos, e se prolonga num número indeterminado de pessoas relacionadas com os desaparecidos. Em K., é o pai, K., quem busca sua filha, A., logo após a sua desaparição. A. era professora universitária e militava num grupo opositor ao regime quando foi raptada pelos agentes da repressão. K. nunca chega a ter notícias de sua filha e não sobrevive à perda incerta dela. Em Palavras cruzadas, passam-se vinte anos até que a protagonista, Sofia, comece a investigar o que aconteceu com seu irmão Leonardo. Nesse meio-tempo, o pai morre e a mãe, Luisa, se encerra na dor e na tristeza. No fim (do romance), a vida de Luisa também se extingue devido à falta de notícias do filho. Mas Sofia acaba por reconstruir em grande parte a vida do irmão antes de morrer: ele participou da guerrilha do Araguaia no início dos anos 70 e não conseguiu escapar do cerco dos militares. Já se entrevê, portanto, que, apesar das semelhanças, os dois livros divergem substancialmente na maneira como discutem o fenômeno do desaparecimento forçado.

Em Palavras cruzadas, o desaparecido não desaparece por completo. Chegam aos familiares anotações de Leonardo sobre suas últimas semanas no Araguaia, antes de cair nas mãos dos militares. Não há, afinal de contas, muito mistério na sua vida clandestina

1. KUCInski, Bernardo. K. Relato de uma busca. São Paulo: Cosac Naify, 2014.

2. Grammont, Guiomar de. Palavras cruzadas. Rio de Janeiro: Rocco, 2015. 
e na perseguição pelos militares. Aquilo que a protagonista não sabe vai descobrindo ao longo da narração, como o fato de ele estar envolvido na execução de um camarada por ordem do partido. Essa deve ter sido inclusive a razão, juntamente com os tormentos da culpa, pela qual ele posteriormente foi para o Araguaia. Mas não só dele se têm notícias, senão também de sua companheira e amada Mariana. Ela começou o diário do treinamento do Araguaia que Leonardo completou depois da volta dela para São Paulo. Como se vê, em Palavras cruzadas os desaparecidos reaparecem em suas narrações sobre a clandestinidade. Sua memória é em grande parte recuperada, e até sua morte, da qual não se têm notícias, pode ser reconstruída por meio de diversos indícios que a narrativa do romance oferece. Dessa maneira, a vida se perde, mas a memória resiste em grande medida ao aniquilamento.

Muito diferente disso, em K. Relato de uma busca a memória da desaparecida (quase) não se reconstrói, e o desconhecimento junto com a incerteza em relação àquilo que aconteceu com A. não se eliminam. Em outras palavras, a memória aqui não é o conhecimento de um passado oculto e sombrio, senão a lembrança constante de que nunca se chegará a saber o que ocorreu e, assim, não há como conter a devastação desencadeada. O romance de Bernardo Kucinski mostra que o desaparecimento forçado é uma estratégia de aniquilamento expansivo. Por esse motivo, ele está no centro do presente estudo. ${ }^{3}$

\section{K. OU A BUSCA DA LITERATURA}

O tempo narrado em $K$. começa no ano de 1974, ou seja, no início do governo do general Ernesto Geisel e do assim chamado período da abertura política. Neste, o regime militar se propõe a abandonar o estado de exceção, os atos institucionais e a suspensão dos direitos constitucionais para voltar a um regime democrático, com "lentidão e gradualidade". 4

3. Também outros textos retratam os danos duradouros da repressão durante a ditadura militar, como, por exemplo, o romance Tropical sol da liberdade (1988; Rio de Janeiro: Alfaguara, 2012), de Ana Maria Machado, ou o conto "Os companheiros", de Caio Fernando Abreu, publicado em Morangos mofados (1982; Rio de Janeiro: Nova Fronteira, 2009, pp. 49-55).

4. Citado em napolitano, Marcos. 1964. História do regime militar brasileiro. São Paulo: Contexto, 2014, p. 238. 
Muito antes de escrever o romance, em 1982, Kucinski publicou Abertura, história de uma crise, uma análise política desse período da ditadura militar brasileira. $\mathrm{O}$ autor mostra que a assim chamada "distensão" não corresponde a uma determinação real em respeitar os direitos humanos e civis, senão a uma estratégia de ganhar respeitabilidade, eliminando alguns instrumentos repressivos do poder para fortalecer o autoritarismo tecnocrático a longo prazo. Segundo o autor, tratava-se de um conflito pelo poder entre a linha moderada dos castelistas (ligada ao general Humberto de Alencar Castello Branco, presidente militar de 1964-1967) e a linha dura (como, por exemplo, os generais-presidente Artur da Costa e Silva e Emílio Garrastazu Médici), que defendia a manutenção do estado de exceção até que a Revolução Redentora fosse completamente realizada. ${ }^{5}$ Kucinski reproduz o pronunciamento de Geisel na primeira reunião ministerial, a 19 de março de 1974, em que o então presidente anuncia "o gradual, mas seguro aperfeiçoamento democrático [...] para a criação de um clima salutar de consenso básico e a institucionalização acabada dos princípios da Revolução de 64". O general-presidente não fala em suspender o estado de exceção, senão em fazer uso menos frequente das medidas de repressão: "Os instrumentos excepcionais de que o governo se acha armado para manutenção da atmosfera de segurança e de ordem" não serão eliminados e continuam à disposição como um recurso último até que o processo de estabilização autoritária os torne desnecessários:

[...] almejo vê-los não tanto em exercício duradouro ou frequente, antes como potencial de ação repressiva ou de contenção mais enérgica e, assim mesmo, até que se vejam superados pela imaginação política criadora capaz de instituir, quando oportuno, salvaguardas eficazes dentro do contexto constitucional. ${ }^{6}$

Como o autor do estudo destaca, tratava-se não de restaurar a democracia mas de consolidar a ordem autoritária, impedindo, ao mesmo tempo, que os nacionalistas de direita

5. Para o uso do termo "revolução" pelos militares golpistas, cf. CHIRIo, Maud. "Le pouvoir en un mot: les militaires brésiliens et la 'révolution' du 31 mars 1964”. Nuevo Mundo, Mundos Nuevos. n. 7, 2007 (http:// nuevomundo.revues.org/3887, visitado em 8 maio 2016).

6. Ernesto Geisel, 19 de março de 1974, citado em KUCINSKI, Bernardo. Abertura, a história de uma crise. São Paulo: Brasil Debates, 1982, p. 20. 
e a linha dura retomassem o poder como tinha ocorrido em 1967, quando o general Costa e Silva se impôs como sucessor a Castello Branco. ${ }^{7}$

O estudo sobre a abertura que Kucinski publica em 1982 é perspicaz e revela que a repressão foi uma peça-chave na luta pelo poder entre os castelistas e os da linha dura, na medida em que Geisel não podia e talvez nem quisesse extingui-la, para que os duros não tivessem um pretexto para opor-se a seu governo. Ao mesmo tempo as tentativas de restringi-la serviam para diminuir o poder de seus rivais. ${ }^{8}$ Como já se mencionou, o interessante é que uns trinta anos mais tarde, Kucinski volta a discutir a fase da distensão, desta vez de forma literária. Logo se nota que de fato várias análises feitas em Abertura, história de uma crise servem de base a $K$. Relato de uma busca. Em questão está principalmente a falsa promessa da abertura do governo de Geisel quando na realidade as práticas da repressão continuam. Esse é o tema do romance, já que trata do desaparecimento da personagem A. durante essa época, o qual K., o pai, não consegue esclarecer. Um exemplo que mostra a estreita relação intertextual entre estudo político e ficção é o pronunciamento do governo, em fevereiro de 1975, a respeito dos desaparecidos. Abertura, história de uma crise discute o acontecimento no capítulo "A crise dos 'desaparecidos" e analisa a versão oficial do governo, em que o ministro da Justiça, Armando Falcão, relata 22 casos de desaparecidos, como uma manobra que somente em aparência cede à pressão da opinião pública. Na verdade, "essa versão nada mais é do que o relatório produzido pelos próprios órgãos de repressão", escreve o autor e acrescenta que a lista do ministro consistia de personalidades conhecidas que não estavam desaparecidas, "para confundir a opinião pública e poder negar o próprio fato de que pessoas 'desapareceram". 9 No romance $K$. o mesmo caso é tratado no capítulo "Nesse dia, a terra parou". O que está em questão aqui é a decepção de K., para quem o anúncio de que o governo daria informações sobre os desaparecidos despertou a grande esperança de

7. Cf. KUCINski, Bernardo. Abertura, a história de uma crise, cit., p. 20. O autor escreve: "Com razão, os 'castelistas' consideravam-se os donos da revolução, não se conformando nunca com o fato de que Castello Branco não conseguiu fazer seu sucessor. Haviam voltado agora, consequência casual da aliança anterior contra os nacionalistas de Albuquerque Lima, e não estavam dispostos a perder de novo o poder" (p. 17). Ver também: KUCINSki, Bernardo. O fim da ditadura militar. São Paulo: Contexto, 2001.

8. Id., pp. 42-3.

9. Id., p. 45 . 
finalmente ter notícias de sua filha. Mas, de maneira análoga a Abertura, a história de uma crise, o personagem logo se dá conta de que a comunicação de Armando Falcão só serve para enganar o público, citando pessoas que nunca desapareceram. "Ao contrário, a falsa lista revelou-se arma eficaz de uma nova estratégia de tortura psicológica. Teria sido melhor não dizerem nada, raciocina K." ${ }^{10}$

A dívida da ficção com a não ficção indica que o romance é uma reflexão literária não somente sobre a ditadura de forma geral, senão, em especial, sobre o período da abertura, que, aliás, não inicia o fim do regime autoritário e sim duplica sua duração, prolongando-o por mais onze anos. Ao mesmo tempo, essa observação levanta a questão de como a análise literária da ditadura se distingue da análise acadêmica. Nesse sentido, $K$. sugere e provoca a discussão sobre a literariedade do romance.

\section{K. OU A BUSCA DO TESTEMUNHO}

Evidentemente, o romance não se propõe a suspender a função referencial da linguagem, ou pelo menos não suspendê-la por completo, mas mantê-la em suspenso. $K$. reflete a ditadura e, mais especificamente, a abertura, como já se observou. Ao mesmo tempo, porém, o romance apresenta um caráter testemunhal. Ele está repleto de referências à realidade comprovada (como, por exemplo, o mencionado relatório do ministro da Justiça sobre os 22 desaparecidos, transmitido por rádio e televisão), mas não alude somente à realidade feita de discursos acadêmicos e jornalísticos, remete igualmente à realidade constituída pela vivência pessoal. É sabido que o protagonista que só se identifica pela letra "K." tem muito da pessoa de Kucinski: a irmã do autor, Ana, foi desaparecida. A filha desaparecida do protagonista K. se chama A. E K. é um judeu polonês que se refugiou no Brasil ainda antes da invasão da Polônia pela Wehrmacht. Kucinski é descendente de imigrantes judeus da Polônia. Ao mesmo tempo, K. certamente não é Kucinski. Apesar da quantidade de referências que se reconhecem como reais, o romance trata de distanciar-se dessa realidade referencial. K. Relato de uma busca claramente cuida de suspender essa realidade, não no sentido de negá-la, porque o tempo todo a afirma referindo-se a ela, mas no sentido de questioná-la ao torná-la irreal ou ficcional, já que

10. KUCINSKI, Bernardo. K. Relato de uma busca, cit., 2014, p. 67. 
simultaneamente se introduzem elementos que abertamente são incongruentes com a realidade factual. No início do livro, o autor adverte o leitor sobre o caráter paradoxal do romance, cuja narração pertence ao mesmo tempo à ficção e à realidade. "Caro leitor: Tudo neste livro é invenção, mas quase tudo aconteceu. B. Kucinski." O que sucedeu está em suspenso - se invoca, mas não se reproduz. Não se rompe com o real, mas se altera sua validade. Insiste-se nos acontecimentos da época e ao mesmo tempo submetem-se os fatos a um estranhamento no qual perdem sua autoridade imediata. Predomina, em outras palavras, a ficção, mas evidentemente ela nunca se desprende da realidade. É como se a ficção estendesse a pertinência do real para além de seu âmbito. Nesse caso, invoca-se uma noção de realidade que não se circunscreve aos fatos.

\section{K. OU A MEMÓRIA DO DESAPARECIMENTO}

Como já se referiu, A. é vítima de um sequestro clandestino praticado por agentes secretos em serviço do regime militar. Mas o livro não se propõe a fazer aparecer o que desapareceu. Nesse sentido, não é a memória da desaparecida, nem a história de seu desaparecimento. Isto é, o romance, em primeira instância, não trata de dar a conhecer o que é desconhecido aos personagens (e aos leitores). Certamente, o romance acaba por dar a entender como sucederam o sequestro e a morte da filha, mas a força do texto não parece nascer dessa explicação. ${ }^{12}$

11. Id., p. 8.

12. O sequestro aparece no capítulo "A cadela", em que um dos sequestradores toma a palavra e se dirige a um ouvinte indeterminado. Depois de confirmar que o rapto do "casal" sucedeu conforme foi ordenado - "do jeito que o chefe gosta, sem deixar rastro, sem testemunha, nada, serviço limpo" -, o narrador se queixa do cachorro das vítimas, que também foi levado e que agora o incomoda (KUCINSKI, Bernardo. K., cit., pp. 63-5). O nome do cachorro é Baleia, o que coincide com uma carta de A., na qual conta a uma amiga que ganhou uma cadela com esse nome (Id., p. 48). A morte de A. é insinuada no relato de Jesuína, uma ex-presidiária que era enviada pelos torturadores às celas de pessoas sequestradas com o intuito de espioná-las. Ela conta como uma "moça", de quem devia extrair informações, somente pronuncia seu nome, "um nome complicado", e se suicida com um veneno que tinha guardado durante sua detenção (Id., pp. 129-30). 
Pelo contrário, o lado forte do texto é não ter fim a busca do pai: ele nunca sabe o que aconteceu com sua filha, nem muito menos encontra o paradeiro de seu corpo morto ou de seus restos. Porém, ele não fica sem saber nada: o desaparecimento obriga o pai a reconhecer que no fundo não conhecia sua filha. K. acaba por descobrir que a filha, antes do desaparecimento forçado, levava uma vida da qual ele não tinha nenhuma ideia. Ele percebe que, em grande parte, desconhecia sua filha, pelo menos no que diz respeito à vida clandestina que ela escondia do pai com o propósito de proteger-se e proteger também a ele. Isso deixa claro que o tema do romance é o que aconteceu não com a desparecida mas com o pai dela. Como se assinalou no início, o livro lê-se como uma reflexão sobre o desaparecimento forçado tal como ele se apresenta aos que perderam um ser querido dessa forma. Nessa perspectiva, a essência nefasta desse crime vai mais além da tortura e do assassinato das vítimas: inflige aos familiares outro sofrimento muito particular, que é a incerteza da morte.

$\mathrm{Na}$ medida em que o romance se nega a ser um documento, mas ao mesmo tempo insiste em sua função testemunhal, a memória que nele se articula aparece como uma memória reflexiva. Quer dizer: ela combina o testemunho com uma visão analítica que não se contenta com o simples relato dos eventos. Nesse sentido, a memória do desaparecimento forçado do romance inclui ou provoca uma reflexão sobre o caráter desse tipo de combate às pessoas que se opunham ao regime militar.

Em primeira instância salta à vista a polifonia do romance, que se narra desde diferentes pontos de vista. Na maioria dos capítulos fala o narrador impessoal e relata as experiências e as atividades de K. na busca de sua filha. Mas em várias partes do livro, esse narrador dá lugar a outras vozes. Em parte elas pertencem a pessoas que comprovadamente existiram. Um exemplo é o próprio Sérgio Fleury, delegado do Dops, temível torturador e sequestrador durante o regime militar. A desaparecida, A., também fala no romance, mas somente de forma intermediada, através de uma carta a uma amiga, que o pai descobre. Por outro lado, as mais diversas e até inesperadas figuras levantam a voz, como a amante de Fleury, ou a já mencionada Jesuína, ex-presidiária, empregada para a limpeza e outros serviços num centro clandestino de tortura em Petrópolis, o qual de fato existia. Enfim, juntam-se várias perspectivas relacionadas ao desaparecimento forçado, mas como visão principal prevalece a do familiar, o pai.

Dessa maneira, o desaparecimento forçado aparece como o problema central da ditadura militar no Brasil. O romance mostra que esse crime de Estado não constitui 
um problema menor, mesmo que apresente números de vítimas muito inferiores às cifras dos desaparecidos nas ditaduras argentina e chilena. ${ }^{13}$ Com isso, ele aponta que a gravidade da devastação que o ciclo das ditaduras militares desencadeou na América do Sul nos anos 1960 e 70 não reside primeiramente na quantidade das vítimas imediatas. Pelo contrário, põe em evidência que o desaparecimento forçado é uma estratégia de extermínio que não se limita à pessoa desaparecida, senão que atinge também seus familiares e de diversas maneiras. É como se o texto literário de Kucinski fizesse uso dos recursos da ficção para dar expressão à dimensão devastadora desse crime do regime militar.

Comente-se que os militares latino-americanos não inventaram esse instrumento de terror. Os nazistas utilizavam o decreto "Nacht und Nebel" ("Noite e novoeiro") para desaparecer com militantes da resistência nos territórios ocupados a partir de 1941. ${ }^{14}$ A França, por sua vez, desenvolveu estratégias de contrainsurgência na Guerra de Independência Argelina entre 1954 e 1962 (na base de suas operações de combate à guerrilha na Indochina nos anos 40). ${ }^{15}$ De passagem seja lembrado que no contexto da guerra na Argélia se desenvolveu a concepção de que na "guerra moderna" o Estado se

13. A respeito da ditadura militar na Argentina, cf. novara, Marcos; PAlermo, Vincente (Orgs.). La dictadura militar (1976-1983): Del golpe de Estado a la restauración democratica. Buenos Aires: Paidós, 2003. Sobre a ditadura de Pinochet, cf. SAlAzAR, Manuel; SEPúlvedA, Óscar: La historia oculta del régimen militar. Chile 1973-1988. Santiago: Antártica; 1990. Para uma visão de conjunto das ditaduras militares na América Latina desde 1930, cf. ANGELL, Alan. "Regímenes dictatoriales desde 1930”. In: POLACios, Marco (Org.). Historia General de América Latina. Paris: Unesco, 2008, vol. viII, pp. 353-71.

14. O decreto servia para aterrorizar as populações locais e visava a que as famílias não soubessem mais nada dos desaparecidos. As vítimas eram secretamente deportadas para a Alemanha. Muitas foram internadas em campos de extermínio. Elas foram executadas ou morriam sem que seus familiares recebessem nenhuma notícia. Cf. o decreto (em versão inglesa) em: http://www.yale.edu/lawweb/avalon/imt/ nightfog.htm (visitado em: 8 maio 2016). Cf. também GruCHMANn, Lothar. "'Nacht- und Nebel'-Justiz. Die Mitwirkung der Strafgerichte an der Bekämpfung des Widerstandes in den besetzten westeuropäischen Ländern 1942-1944". Vierteljahrshefte für Zeitgeschichte. Stuttgart, n. 29, caderno 3, pp. 342-396, 1981. O escritor Jean Cayrol fez parte da resistência na França e foi deportado para o campo de concentração de Mauthausen-Gusen. Em 1946 ele publica a antologia poética Poèmes de la nuit et du brouillard (CAYrol, Jean. Poèmes de la nuit et du brouillard. Paris: Éditions du Seuil, 1995). Ele também escreve o roteiro do documentário Nuit et brouillard, dirigido por Alain Resnais e lançado em 1955 (RESNAIS, Alain. Nuit et brouillard. França, 1955).

15. Cf. robin, Marie-Monique. Escadrons de la mort, l'école française. Paris: La Découverte, 2004. 
vê confrontado com forças subversivas que lutam para derrubá-lo. Para defender-se, ele teria que mudar radicalmente a estratégia militar. O inimigo agora é interno, a guerra se trava no interior da sociedade e o combate deve dar-se através de comandos pequenos e móveis, empregando táticas para desestruturar o inimigo como, por exemplo, a tortura. ${ }^{16}$ É sabido que essa "Doutrina da guerra revolucionária" foi ensinada aos militares sul-americanos. ${ }^{17}$ E que também os Estados Unidos se interessaram e a incorporaram no programa da Escola das Américas no Panamá, outro centro de desenvolvimento e ensino de doutrinas de contrainsurgência. ${ }^{18}$ Especialmente na Argentina, o desaparecimento forçado é discutido como uma prática estatal de extermínio que se relaciona de diversas maneiras com a shoah. ${ }^{19}$

Um romance argentino que reflete as práticas clandestinas de detenção, tortura e assassinato dos militares naquele país nos anos 70 é Dos veces junio (2002), de Martín Kohan. Ao contrário de K., a busca de uma pessoa sumida por seus familiares não está no centro da narração. O protagonista é um jovem recruta que conta em primeira pessoa sua história como motorista de um médico militar que está envolvido na tortura. Dos veces junio põe em cena a educação do jovem pelo médico, que vai assumindo a visão de mundo dos militares. Num dos momentos decisivos do romance, quando o protagonista espera seu superior num dos corredores do Pozo de Quilmes - um centro de detenção e de maternidade clandestino do regime militar argentino -, uma prisioneira reclusa numa das celas dá-se conta de que o recruta se encontra nesse lugar sem ser torturador. Ela apela à consciência dele e pede-lhe um favor: a detenta suplica-lhe que comunique a seu advogado onde se encontra: "Ella mientras tanto me decía: 'Yo te doy el número de un abogado y vos avisás dónde estamos. Nada más. Das el aviso y cortás. Nada más. A vos no te va a pasar nada". ${ }^{20}$ Isto é, a detenta tenta dar a conhecer sua situação e sua localização. Muito provavelmente, ela não tinha esperanças de sair dali com vida, mas sua estratégia é dar notícias de seu paradeiro e reaparecer. Não desaparecer por completo, ainda que percam a vida, é a última resistência dos detentos. O mesmo

\footnotetext{
16. TRINQUIER, Roger. La guerre moderne. Paris: La Table Ronde, 1961.

17. RовIN, Marie-Monique. Escadrons, cit., p. 175.

18. GILL, Lesley. The School of the Americas. Military Training and Political Violence in the Americas. Durham: Duke University Press, 2005.

19. Cf. FeIERSTEIn, Daniel. El genocidio como práctica social. Entre el nazismo y la experiencia argentina. 2. ed. México, D. F.: FCE, 2011.

20. коHAN, Martín. Dos veces junio. Buenos Aires: Debolsillo, 2013, p. 136.
} 
motivo se encontra em K., como já se assinalou, no depoimento de Jesuína, que, entre outras coisas, relata que as únicas e últimas palavras de uma presa que, como deduz o leitor, é ou poderia ser A., é o pronunciamento de seu nome:

Me colocaram na cela dela, sem falar nada, e eu tentei puxar conversa. Ela me disse o nome dela e depois não falou mais nada. Disse o nome completo, acho que completo, mas eu só guardei metade, era um nome complicado. Disse assim recitado como quem sabe que vai morrer e quer deixar o nome, para os outros saberem. ${ }^{21}$

A presa sabe que vai morrer e de fato se antecipa a seu assassinato tomando veneno. Já sem poder contar com a vida, tenta, como se vê, ao menos comunicar a alguém quem ela é, para impedir assim que não exista nenhuma notícia dela, de sua morte e de suas circunstâncias. $O$ fato de que Jesuína não lembre e não diga o nome da vítima mostra que no romance não se consegue superar o desaparecimento. A prisioneira de Quilmes, em Dos veces junio, não teve outra sorte: o eu narrador não está disposto a escutá-la nem a ajudá-la. O nome dela também não se chega a saber. A mulher insiste e revela ao jovem soldado que no fundo não se trata dela, mas do filho que nasceu ali; contudo, o protagonista não se comove, já tinha começado a adotar a postura de médico-oficial, de que a vida de um prisioneiro não tem valor:

Yo le dije que estaba harto de escucharla. Me pidió que le salvara al hijo, que llamara desde un teléfono público para decir dónde los tenían y que después cortara la comunicación. "Estás muerta, hija de puta", le decía yo, y ella me decía que avisara por el hijo. "Cállate de una vez", le dije yo, "no hables más, hija de puta, no ves que ya estás muerta." Y ella me pedía por el hijo y por los compañeros. ${ }^{22}$

21. KUCINSKI, Bernardo. K. Relato de uma busca, cit., p. 129.

22. KoHAN, Martín. Dos veces junio, cit., p. 139. Da prisioneira não se fala mais no romance - mas seu filho é a presa que o médico trata de obter para fazê-lo chegar a sua irmã que não pode ter filhos. O motivo do filho roubado por militares também se encontra em Palavras cruzadas (2015) de Guiomar de Grammont. Nesse romance, Sofia, a protagonista, chega a esclarecer em grande parte o desaparecimento de seu irmão Leonardo vinte anos antes. E no final descobre que esse teve uma filha. Ela encontra a sobrinha e reconhece o irmão na jovem: "Só então, depois de mal suportar, o dia todo, a ansiedade, teve certeza: as covinhas no rosto de Cíntia quando ela sorria, seus olhos cor de mel encimados por longos cílios, ela era inteira... Leonardo. Tanto mais parecida porque a moça era 
O livro de Kucinksi mostra que a contrainsurgência se dirige em primeira instância contra o corpo do inimigo interno. Mas ele também destaca que o aniquilamento vai muito além da agressão física. Não se tratava de matar senão de destruir, e essa destruição podia ser também com vida. O que está em questão é que a tortura visa a aniquilar não só o inimigo interno mas também o inimigo interior, que se esconde na esfera íntima do combatente. Este é um inimigo duplamente invisível: ele se esconde no meio da população e ele dissimula suas intenções. O combate se dá através da inflição da dor. No romance, a tortura só aparece de forma marginal e mediada, através da fala de outros. Mas o impacto é forte. Jesuína, empregada na casa de Petrópolis, confessa-se com uma psicoterapeuta sobre o que ela viu no centro de tortura; é sintomático para sua traumatização que os acontecimentos em Petrópolis a estejam alcançando só meses depois e que estejam devastando sua vida no presente: "Não, eu não me importava, eu ia porque ia, gostava. As alucinações começaram depois, depois que a casa fechou..... ${ }^{23} \mathrm{O}$ trauma da personagem foi provocado por ter visto não a tortura mas os torturados: “[...] eu servia os presos, limpava as celas, tentava me fazer de boazinha. A cara deles era de apavorar, os olhos esbugalhados; tremiam, alguns ficavam falando sozinhos, outros pareciam que já estavam mortos, ficavam assim meio desmaiados.... ${ }^{24}$ Para aniquilar o inimigo interno, não é necessário

jovem como ele era, quando Sofia viu o irmão pela última vez" (GRAmmont, Guiomar de. Palavras cruzadas, cit., p. 227). No romance de Grammont, o roubo da criança é amenizado pelo arrependimento do militar que a adotou ilegalmente e que faz chegarem as anotações de Leonardo e Mariana, a mãe da sobrinha, aos familiares do desaparecido. Essas anotações foram feitas durante a guerrilha do Araguaia, da qual participaram e onde Leonardo foi capturado, com o manuscrito. Quer dizer que, mesmo que a protagonista não chegue a conhecer as circunstâncias concretas da morte do irmão (e da companheira), ela obtém não somente notícias como extensos relatos - redigidos pelos próprios - de sua participação na guerrilha. Além do mais, com o encontro da sobrinha, é como se o irmão ressuscitasse. Por esses motivos, seria mais justo falar não em desaparecimento mas em reaparecimento no caso de Palavras cruzadas.

23. KUCINSKI, Bernardo. K. Relato de uma busca, cit., p. 124.

24. Id., p. 128. A destruição do inimigo pela tortura é um dos temas centrais de Dos veces junio. O romance abre com a questão de com que idade se poderia começar a torturar uma criança. Assim se inicia a narração: "El cuaderno de notas estaba abierto, em medio de la mesa. Había una sola frase escrita em essas dos páginas que quedaban a la vista. Decía: ‘ $A$ partir de qué edad se puede empesar a torturar a un niño?”' (KоHAN, Martín. Dos veces junio, cit., 11). O único incômodo do eu narrador ao ler a anotação é um erro ortográfico em "empesar" ( $s$ em vez de $z$ ). O menino em questão é o da > 
matá-lo. Sua desestruturação através da tortura pode ser suficiente. A tortura se dirige ao corpo, mas ela visa a quebrar a pessoa. Porém, muitos torturados não sobreviveram, e o romance fala deles.

Como já ficou assinalado, a devastação assim desencadeada destina-se também aos familiares e não cessa com a morte. Com a tortura e o desaparecimento, a própria morte se desestabiliza: a morte deixa de ser o fim de uma vida. Nesse sentido, a finalidade da tortura é eliminar a vida antes da morte. Mas para os familiares, o desaparecido nunca termina de morrer. Para K., a filha desaparecida nunca morre completamente. Ele continua buscando-a muito depois de saber que está morta. Escutemos a fala do Fleury que sequestrou A. e que saboreia o sofrimento do pai:

Mineirinho, você viu como deu certo o lance com o Fogaça? Só que não é nada do que você está pensando, Mineirinho. O velho não veio porque acreditou, Mineirinho. Esse velho é esperto. Ele veio porque tinha que vir. Ele tinha que vir, entendeu? Mineirinho, aí é que está o truque, a psicologia. Ele tinha que vir, mesmo não acreditando. E sabe por quê? Porque se ele está correndo atrás desses figurões, mesmo depois desse tempo todo, é porque não quer aceitar que a filha já era. Se recusa. Daí se agarra em qualquer coisa, mesmo sabendo que é armação. Não pode deixar de ir, de tentar. Sabe de uma coisa, Mineirinho, foi uma puta ideia essa que eu tive. ${ }^{25}$

Finalmente, a morte da filha estende-se ao próprio pai, que se abala e definha não propriamente com a morte da filha, mas com o não aparecimento dessa morte.

\footnotetext{
$>$ prisioneira que tenta comunicar-se com o eu narrador, e o médico-oficial somente impede sua tortura porque o queria para sua irmã.

25. KUCINSKi, Bernardo. K. Relato de uma busca, cit., p. 70-71. Que os desaparecimentos forçados ameaçam devastar os familiares é demonstrado em estudos de caso. Um exemplo é o relatório da Comissão da Verdade de El Salvador denominado De la locura a la esperanza. La guerra de 12 años de El Salvador. Nele, descreve-se não só, entre outros, o desaparecimento de Sara Cristina Chan Chan em junho de 1980, como também a via-crúcis de sua mãe e como foi mandada de uma instalação militar e policial a outra. Ao contrário do que as indicações dos oficiais prometiam, a mãe nunca encontrou nenhum rastro de sua filha. Pelo contrário, a senhora chegou a ser ameaçada diretamente. Um oficial da Força Aérea chegou a dizer-lhe que, se voltava, "lhe ia passar o mesmo" (NACIONEs UnidAs [org.]. De la locura a la esperanza. La guerra de 12 años de El Salvador. Naciones Unidas: San Salvador; New York. 1992-1993, pp. 114-5).
} 
No fim, ele consegue uma entrevista com prisioneiros políticos no quartel de Barro Branco. Quando K. entra no quartel, é invadido pelas memórias de sua própria prisão cinquenta anos antes na Polônia: "Sentia-se muito cansado. Haviam se passado catorze meses da impensável desaparição da filha". ${ }^{26} \mathrm{~K}$. é arrebatado pela sensação de que meio século passou em vão: "cinquenta anos de nada", o que significa que durante sua vida nada mudou; a perseguição e o extermínio persistem, a história não progrediu e esvazia-se de sentido. Suas forças extinguem-se e ele morre momentos depois no quartel.

Nesse sentido, o livro é um caleidoscópio das destruições progressivas e crescentes provocadas pelo desaparecimento forçado. Além da tortura psicológica do pai, descreve-se a cumplicidade de pessoas e instituições: um exemplo é a universidade, que cede às pressões dos militares e demite A. pelo abandono de suas funções, aproveitando a demissão para contratar um professor aposentado. Outro exemplo é o rabino que impede que o pai erija uma matzeivá, uma lápide, para a filha, alegando a ausência do corpo.

No entanto, o mais terrível é o envolvimento da própria vítima com a culpa. K. acaba por culpar-se pela morte da filha: por não ter estado atento ao que acontecia e por ter-se interessado unicamente pela literatura - nesse caso em iídiche. Ele percebe que, devido a sua preocupação pela literatura, ignorava a situação da filha e o perigo em que ela se encontrava.

Também os sobreviventes daqui estão sempre a vasculhar o passado em busca daquele momento em que poderiam ter evitado a tragédia e por algum motivo falharam [...]. Porque é óbvio que o esclarecimento dos sequestros e execuções, de como e quando se deu cada crime, acabaria com a maior parte daquelas áreas sombrias que fazem crer que, se tivéssemos agido diferentemente do que agimos, a tragédia teria sido abortada. ${ }^{27}$

26. KUCINSKI, Bernardo. K. Relato de uma busca, cit., p. 172.

27. Id., p. 168. 


\section{K. OU O DESAPARECIMENTO QUE NÃO TERMINA}

A memória, tal como é concebida no livro, não tem a ver só com o registro dos crimes. No fundo, ela não recupera o passado, e sim mostra que aquela violência não se reduz a vulnerações ocorridas anteriormente, senão que ela está presente e vigente. Quer dizer que a memória não recupera o que passou, mas, ao contrário, deixa em evidência que a devastação continua: o desaparecimento não termina, o aparelho de repressão continua intacto, os assassinos estendem seu triunfo aos que ainda vivem e inclusive à geração posterior. Quem narra o romance é, como já se ressaltou, um narrador impessoal. Mas ele dá-se a conhecer, no início e no fim do livro. Há uma espécie de prólogo que se diferencia do resto da narração pelo uso do itálico. O capítulo inicial termina com local e data: "São Paulo 31 de dezembro de 2010". Aqui, o narrador se apresenta em primeira pessoa, e conta que continuam chegando cartas do banco a "ela", a desaparecida. Parece que é o autor que fala - mas esse narrador também é ficção. No final do livro está o "Postscriptum", também em itálico. Nessa espécie de epílogo, o narrador finalmente se dá a conhecer, de forma indireta: ele é o irmão da desaparecida, que nunca aparece como personagem na narração:

\footnotetext{
Passadas quase quatro décadas, súbito, não mais que de repente, um telefonema a essa mesma casa, a esse mesmo filho meu que não conheceu sua tia sequestrada e assassinada; voz de mulher, apresenta-se, nome e sobrenome, moradora de Florianópolis. Diz que chegara havia pouco do Canadá, onde fora visitar parentes e que conversavam em português numa mesa de restaurante quando se aproximou uma senhora e se disse brasileira dando seu nome completo, o nome da tia desaparecida. A voz feminina deixou seu nome, para contatos. ${ }^{28}$
}

O livro dói, porque nega uma visão conciliadora: ele não recupera o que está perdido. É, antes, um panorama de desolação em que nem a literatura redime. Como acima se assinalou, K. reconhece que contribuiu para o desaparecimento da filha, já que foi por causa do seu entusiasmo literário que deixou de estar atento às mudanças na vida de A. O romance deixa transparecer uma visão cética da literatura: ela não constitui um fim em si mesma e não supera a perda. Ao mesmo tempo, K. Relato de uma busca é

28. Id., p. 181. 
literatura e mostra - comparando o romance com estudos factuais sobre o período da abertura - que só ela é capaz de dar expressão à dimensão devastadora do desaparecimento forçado. O que vemos no romance é que o extermínio não é detido, nem pelo tempo, nem pelo tratamento literário. Nem a literatura se contrapõe ao aniquilamento: A. nunca mais recupera presença e existência. O irmão, que durante a narração da busca do pai nunca parece envolver-se com a desaparição de A., acaba por ser afetado, sem que isso se explicite no texto. Porém, o fato de ser ele quem narra a história evidencia que as perdas tanto da irmã como do pai o levaram a contar o que aconteceu. Ao atender o último telefonema, até o sobrinho, que nunca conheceu a tia, é vulnerado pela continuação do desaparecimento de A.

Joachim Michael é Professor da Universitat Bielefeld. 